\title{
The Geographic Distribution of Nurse Practitioners in the United States
}

\author{
GE LIN \\ Population Studies Center \\ University of Michigan \\ Ann Arbor, Michigan 48104 \\ PATRICIA A. BURNS \\ College of Nursing \\ University of South Florida \\ Tampa, Florida 33620 \\ THOMAS H. NOCHAJSKI \\ Research Institute on Addictions \\ Buffalo, NY 14203
}

Received May 1997; accepted August 1997

\begin{abstract}
This study analyzed the geographic distribution of nurse practitioners in the United States. Primary data on nurse practitioners were obtained from State Boards of Nursing and the District of Columbia in the spring of 1994. At the state level, nurse practitioners were more concentrated in urban areas than their physician counterparts. Of the 33,094 certified nurse practitioners, $85 \%$ were in metropolitan areas. Results from the dissimilarity indices between nurse practitioners and general populations showed that a greater supply of nurse practitioners in a state may not necessarily lead to an equitable distribution across counties. At both the state and county levels, the supply of nurse practitioners was positively associated with the supply of primary care physicians. Results from multivariate analyses show that nurse practitioners were more likely to locate in a county where state laws allowed independent practice. States that allow independent practice and direct third-party reimbursement will likely have greater availability and a larger supply of nurse practitioners in rural counties. () 1997 John Wiley \& Sons, Inc.
\end{abstract}

Keywords: nurse practitioner-to-population ratio; geographic distribution; health-care policy

Reprint requests should be directed to: Ge Lin, gelin@umich.edu.

Acknowledgments: We appreciate the helpful comments of Evelyn Moses, Michael Hayes, and four referees. This study was partially supported by the Federal Office of Rural Health Policy Education initiatives and the New York State Commission on Rural Resources. 


\section{INTRODUCTION}

Nurse practitioners have consistently been the largest group of non-physician health care providers in the United States [Graduate Medical Education National Advisory Committee (GMENAC), 1981; Jones and Cawley, 1994]. With the United States still facing a shortage of primary-care physicians in many under-served areas, some have suggested that efforts be made to encourage the use of nurse practitioners to improve access to care for under-served populations (Safriet, 1992; DeAngelis, 1994). These voices are echoed in recent reports regarding health manpower policies. Both the Vector report (U.S. Department of Health and Human Services, 1995) and Pew Health Professions Commission report (1995) recognized the unique contributions of nurse practitioners to health promotion, disease prevention, and reaching the hard-to-reach population. It was recommended that these roles be emphasized, and nurse practitioner training programs be expanded.

Although the cost effectiveness of nurse practitioners has long been established (Spitzer et al., 1974; Brown, 1988; Martin and Martin, 1991), little is known about their geographic distribution, in particular, about their role in serving populations in underserved areas. ${ }^{1}$ As a result, our knowledge on nurse practitioners' role in the health-care work force is very limited (Aiken and Salmon, 1994; Koch, Pazaki, and Campbell, 1992; Hadley, 1994). In response to this knowledge gap, the Physician Payment Review Commission 1994 report (PPRC, 1994) and the 1992 National Sample Survey of Registered Nurses (Division of Nursing, 1994) were both commissioned to assess the current status of nurse practitioners. The National Sample Survey of Registered Nurses, which was based on a representative sample of 2,609 respondents, estimated that there were 29,965 certified nurse practitioners in the United States. The Physician Payment Review Commission (1994), which was based on a very broad definition of nurse practitioner, reported that an estimated 48,000 RNs had some type of training as a nurse practitioner. A nurse practitioner is a registered nurse who has had, in general, 18 months of training, half of which is in clinical practice (PPRC, 1994). Because the estimates from these reports differed so greatly, and neither reported estimates of nurse practitioners at the state level, it is necessary to independently estimate nurse practitioner population at the national and state levels.

Conventional wisdom holds that rural and inner city areas are under-served, and the federal funding for nurse practitioner programs, which began in the 1970s, was specifically targeted at improving health care access to these areas (Office of Technology Assessment, 1986). In the early years, these programs were fairly successful in meeting this goal (Sullivan et al., 1978; Sultz et al., 1983b). In 1981, there were 12,000 nurse practitioners more or less equitably distributed according to general populations. For instance, a national longitudinal study between 1976 and 1981 (Sultz and Zielezny, 1976; Sultz et al., 1980; Sultz et al., 1983a) found that $22 \%$ of nurse practitioner graduates were employed in rural areas and $23 \%$ in inner city settings. However, as nurse practitioners grow in number, their distribution moves increasingly toward urban areas (Office of Technology Assessment, 1986). In a national study of 44 rural satellite health centers, Brooks and his colleagues (Brooks et al., 1981; Brooks and Johnson, 1986) found that

\footnotetext{
${ }^{1}$ According to the U.S. General Accounting Office (GAO) (1995), under-served areas usually have signs of overuse of emergency rooms, long waits for an appointment, and a lack of preventive care services. The term under-served area is often used interchangeably with health care shortage area, which is defined by a populationto-physician ratio of at least 3,500 to 1 .
} 
the number of nurse practitioners had declined 38\% between 1975 and 1984. Although the Office of Technology Assessment (1986) speculated that this trend would continue into the early 1990s as a result of increased supply of primary-care physicians in rural areas, no one has examined this issue. In fact, the geographic distribution of nurse practitioners has not been studied, despite the fact that the Graduate Medical Education National Advisory Committee had recommended a study of this phenomenon 15 years ago (GMENAC, 1981).

Factors affecting nurse practitioners' distribution are also an under-studied area. Although very few studies are devoted to this subject, from an economic geography perspective, it can be speculated that factors important to physician location preferences should behave in a similar way to those of nurse practitioners (Ernst and Yett, 1985; Rivo and Satcher, 1993). Laws or regulations governing nurse practitioners' practice can potentially cause a difference in distributions of nurse practitioners and physicians. In general, nurse practitioners often practice under the supervision of a collaborating physician, but the laws and regulations vary between states, and these variations affect the ability of nurse practitioners to serve in underserved areas. In the study of state practice environment for physician assistants, nurse practitioners, and nurse-midwives, Sekscenski et al. (1994) found that a favorable state legal environment for nurse practitioners is associated with a greater supply of nurse practitioners. But it is unclear if state laws or regulations would affect the distribution of nurse practitioners within a state, in terms of serving under-served populations. To answer this question, one needs to evaluate the distribution of nurse practitioners at a finer geographic scale. The current study utilized the actual number of registered/certified nurse practitioners in each state and the District of Columbia to analyze their geographic distribution at both state and county levels. ${ }^{2}$ Specifically, this study investigated the following research questions:

1. How are nurse practitioners distributed nationally along a rural-urban continuum?

2. What is the relationship between the distribution of nurse practitioners and primarycare physicians?

3. What are the differences between the distribution of nurse practitioners in relation to the general population within a state? How are state legal environments for nurse practitioners associated with the availability and the supply of nurse practitioners?

\section{METHODS}

\section{Building the National Nurse Practitioner Data Base}

Both state boards of nursing and the American Nurses Credential Center provide rosters of nurse practitioners, but the former requires regular re-certification, which provides more updated certification status and address information. For this reason, we acquired rosters of certified or registered nurse practitioners mainly from state Boards of Nursing (including the District of Columbia) between January and April of 1994. For states in

\footnotetext{
${ }^{2}$ We realize that "county" may not be the best area unit for this analysis. We used it because of the availability of other data sources. Data on nurse practitioner distributions are available upon request, so other researchers may explore the "best" area unit for analyzing geographic distribution of nurse practitioners.
} 
which records were not available (New Jersey, Colorado, Hawaii, Illinois, Indiana, Minnesota, Ohio, Tennessee, and Wisconsin), listings of certified nurse practitioners were obtained from the American Nurses Credential Center. Nurse practitioners were geocoded by ZIP codes to identify the county where the certification was issued; when a ZIP code crossed a county boundary, address matching was performed (this process involves less than $3 \%$ of the nurse practitioner population). This yielded nurse practitioner populations for each county. In addition, for purposes of describing county characteristics (e.g., other health professions and socioeconomic indicators), the 1993 Area Resource File (U.S. Department of Health and Human Services, Bureau of Health Professions, 1994) was matched with the nurse practitioners in each county.

There are three issues related to the compilation of the National Nurse Practitioner data base. First, nurse practitioners may be certified by multiple states. In cases where names and street addresses were identical, those with most recent certification were kept and other duplicates were deleted. When the names were duplicated but not the addresses, both records were retained (nationally there were fewer than 30 cases with identical names but different addresses). This process resulted in the deletion of 1,300 duplicated nurse practitioner names. Washington and New Hampshire also included Midwives and Nurse Anesthetists in their records; we deleted these advanced registered nurses by matching our lists with the lists from the American College of Nurse Midwives and the Nurse Anesthetists Certification rosters in these states. An additional 600 cases were deleted in this process.

Second, although all the nurse practitioners in our data base have an active certification, they may not be functioning/practicing as a nurse practitioner. Most states do not keep track of nurse practitioners' employment status. However, this may not pose a serious problem. As part of a bigger project, we drew a $10 \%$ sample from the data base, and asked about respondent's employment status. It was found that $15.7 \%$ were not currently employed as nurse practitioners, and among them only $1.9 \%$ were age 65 or older. These results indicate that most inactive nurse practitioners are potential primary health care resources.

Third, like many studies of health professional distributions, we recognized that potential bias can be generated by commuters across county or state boundaries. As indicated above, a nurse practitioner can only be identified to the address where the certification was issued, which can be a health clinic or a residence. If a nurse practitioner practices in a county and lives in another county, the county of residence will be over represented in the analysis. Because the primary-care physician master file used in this study has a similar problem, we assumed that nurse practitioners and physician commuters across state or county lines are only small portions of the corresponding populations, and some of the cross-county practices may offset each other. Although this assumption may not be valid for certain counties, the bias estimates caused by crosscounty commuters are likely to be small for most parts of the country. According to the Office of Management and Budget (1990), if more than 15\% of commuters across a county line in a metropolitan area, the two counties can be considered as one geographic area for statistical purposes.

\section{Data Analysis}

In addition to the commonly used method of comparing nurse practitioner-topopulation ratios in different areas, the corrected Duncan-Duncan Dissimilarity Index (Coulter, 1989, pp. 142-146) was used to compare the distributions of nurse practition- 
ers and primary-care physicians by county within each state. This index is frequently used to evaluate residential segregation at different geographic levels, where one racial group distribution is compared with another racial group. For $r$ counties, the formula is

$$
I D=\frac{\sum_{I}^{r}\left|N P_{i}-P_{i}\right|}{2(1-\min P)}
$$

where $P_{i}$ is the fraction of the state population found in county $i, N P_{i}$ is the fraction of the total nurse practitioner population of a state in county $i$, and $\min P$ is the smallest $P$ value. It compares the distribution of one population group with a reference population group to determine the similarity of the groups' geographic distribution. This index ranges from 0 to 1 . An index value of 0 would indicate no difference between the two groups, or perfect equity. An index value of 1 would indicate the most dissimilar pattern.

Distinctions between rural and urban settings were based on a continuum known as the Beale code, which was developed by the U.S. Department of Agriculture (Hewitt, 1989). The Beale code has 10 categories, ranging from counties with urban populations of more than 1 million to counties with populations of less than 2,500. Unlike commonly used metropolitan versus non-metropolitan definitions, the Beale code has four categories that are designated as metropolitan and six that are designated as non-metropolitan. The non-metropolitan categories are differentiated by the size of their urban populations and their proximity to metropolitan counties.

After analysis of nurse practitioner distribution at the national and state levels, logistic regression and multiple regression analyses were used to examine the influence of a set of factors on nurse practitioner distribution at the county level. Because there are more than 1,000 counties that do not have any nurse practitioners, the logistic regression is appropriate for assessing factors associated with the likelihood of having at least one nurse practitioner in a county. For those counties having at least one nurse practitioner, we assess the supply of nurse practitioners using multiple regression. In the logistic regression, the dependent variable predicts the likelihood of having at least one nurse practitioner in a county. In the multiple regression, the county-level nurse practitionerto-population ratio was the dependent variable. In both analyses the independent variables were grouped as health services, sociodemographic factors, legal environment, and rural factors. All of the independent variables, except those pertaining to legal environments, are from the Area Resource File. Multicollinearity among independent variables was checked via variance inflation factors and the correlation matrix, and found not to be significant.

The primary-care physician growth rate, which was based on the change in the number of primary care physicians between 1985 and 1992, was a key independent variable. As mentioned earlier, the Office of Technology Assessment asserted that increases in primary care physicians in rural and other areas would lead to decreases in nurse practitioners. Although this hypothesis cannot be tested with the cross-sectional data, it implied that counties with greater increases in primary care physicians have fewer nurse practitioners; after purging the effect of the total supply of physicians or physician-topopulation ratio in each county.

Other health service and sociodemographic variables are included primarily because of their importance in physician location literature (Schwartz et al., 1980; Newhouse et al., 1982; Langwell et al., 1987). Because health maintenance organizations tend to employ proportionately more nurse practitioners than other health care organizations (Weiner, 1993; Weiner et al., 1986), a dummy variable of existence of an HMO mem- 
bership organization was included. For purposes of assessing whether prior existence of nurse practitioners would have an effect on their current distribution, the presence of at least one nurse practitioner in 1980 was included as a factor in the analyses. Hospital beds per 1,000 population was used to account for the overall level of hospital services. Several variables (median home value, per capita income, and poverty rate) depicting county socioeconomic characteristics were also included. Additionally, two variables were devised to measure the rural environment. Using the Beale code a binary variable measuring residence was created. Counties where nurse practitioners practice or reside were coded 0 for metropolitan and 1 for non-metropolitan counties. The other measure of the rural environment, population density, defined as the number of persons per square mile, is a global measure of rural attributes.

Sekscenski et al. (1994) classified states on their legal environments for nurse practitioners with respect to legal status (or scope of practice), reimbursement, and prescriptive authority. The higher the score, the less restrictive the legal environment. It was found that the nurse practitioner-to-population ratio is positively correlated with the total score of state (legal) practice environment. Safriet (1992, 1994), in her review of state regulation, identified three major barriers to nurse practitioners: scope of practice, prescriptive authority, and reimbursement. Each of these have different impacts on the distribution of nurse practitioners. For the purpose of making the analysis relevant to specific regulatory provisions, we adopted the Safriet approach, and reviewed each state's regulations on nurse practitioners. We found two factors to be the most consistently defined in each state law or regulations-scope of practice and reimbursement-and prescriptive authority is often closely related to the scope of practice [see also Safriet (1992)]. For this reason, two dummy variables were included in the analysis: states allowing independent practice and direct third-party reimbursement were contrasted with states not allowing independent practice and third-party reimbursement, respectively.

\section{RESULTS}

\section{Nurse Practitioner Distributions at the National and State Levels}

There were 33,094 certified nurse practitioners (active and inactive) in the United States in 1994. Of the total, $85 \%(28,142)$ were located in metropolitan counties and $15 \%$ in non-metropolitan counties (Table 1). A further breakdown based on the urban-rural continuum showed that only $5.48 \%$ of nurse practitioners were located in remote rural counties (Table 1, fourth column). At the other end of the spectrum, $52.02 \%$ of the nation's nurse practitioners were located in large metropolitan counties, and $9.40 \%$ were concentrated in the four metropolitan counties that include the cities of Los Angeles, San Diego, Boston, and Seattle. Of the 3,140 counties in the United States, 2,038 had at least one nurse practitioner. In those counties, the mean number of nurse practitioners was 16 , with a median of three.

When we compared nurse practitioner distribution with population distribution, we found that nurse practitioners were disproportionately located in urban counties with large central cities. In a pattern similar to that of primary-care physicians, only a small proportion of nurse practitioners was located in rural areas. Nurse practitioners, however, were more likely than primary-care physicians to locate in large urban areas. 
Distribution of Nurse Practitioners

TABLE 1 • Rural-Urban Distribution of Nurse Practitioners in the U.S., 1994

\begin{tabular}{|c|c|c|c|c|c|}
\hline \multirow[b]{2}{*}{ Variable } & \multicolumn{2}{|c|}{ Metropolitan } & \multicolumn{2}{|c|}{ Nonmetropolitan } & \multirow[b]{2}{*}{ Total } \\
\hline & $\begin{array}{c}\text { Large } \\
\text { metro-core }\end{array}$ & $\begin{array}{c}\text { Median- } \\
\text { large metro }\end{array}$ & Nonmetro I & Nonmetro II & \\
\hline NPs & $52.02 \%$ & $33.02 \%$ & $9.49 \%$ & $5.48 \%$ & 33,094 \\
\hline Population $(1,000)$ & $27.86 \%$ & $48.55 \%$ & $14.07 \%$ & $8.63 \%$ & 248,708 \\
\hline Primary-care $\mathrm{MDs}^{\mathrm{b}}$ & $38.78 \%$ & $48.04 \%$ & $8.58 \%$ & $4.61 \%$ & 218,698 \\
\hline
\end{tabular}

aLarge metro-core refers to core metropolitan counties with population greater than 1 million (Beale's code 0). Median-large metro refers to noncore metropolitan counties (Beale's code 1-3) with population equal to or less than 1 million. Nonmetro I refers to nonmetropolitan counties with population either above 20,000 or between 2,500 and 20,000 but adjacent to metropolitan counties (Beale's code 4-6). Nonmetro II refers to nonmetropolitan counties with population below 20,000 but not adjacent to metropolitan counties (Beale's code 7-9). All these are based on the 1992 Beale code.

bThe source for numbers of primary-care physicians is the 1993 Area Resource File. Primary-care physicians include general and family practitioners, internists, pediatricians, and obstetricians/gynecologists. There were 1,225 primary care physicians and 442 general or family physicians who could not be matched with the rural/urban continuum code.

To examine the distribution of nurse practitioners by state, the dissimilarity index discussed earlier, nurse practitioner-to-population ratio and nurse practitioner-primarycare physician ratio were calculated for each state (Table 2). The results showed that Alaska had the highest nurse practitioner-to-population ratio (40 nurse practitioners per 100,000 population), and Illinois had the lowest (4 nurse practitioners per 100,000 population). To compare nurse practitioner-to-population ratios between states, nurse practitioner-to-population quotients were derived by dividing the national average nurse practitioner-to-population ratio (13.306) by each state's nurse practitioner-to-population ratio (Table 2, third column). The nurse practitioner-to-population quotients indicated that 20 states had nurse practitioner-to-population ratios above the national average, and 30 states and the District of Columbia were below the national average (quotient $<1$ ). States with relatively high nurse practitioner-to-population ratios were in the New England and West Coast regions; states with the lowest nurse practitioner-to-population ratios were in the Great Lakes area and in the South.

It has been speculated (Office of Technology Assessment, 1986) that nurse practitioners may be displaced as the number of primary-care physician increase in underserved areas. If this were true, we would expect an inverse relationship between the supply of nurse practitioners and the supply of primary-care physicians. However, the nurse practitioner-to-population ratio was highly correlated with the number of nurse practitioners per 100 primary-care physicians $(r=.938, p<.001)$; states having higher nurse practitioner-to-population ratios also had higher nurse practitioner-to-primary care physician ratios. At least at this stage of development, nurse practitioners have not been squeezed out by primary-care physicians at the state level. The fact that the majority of states require that nurse practitioners be supervised (directly or indirectly) by a collaborating physician may help explain why the supply of nurse practitioners parallels that of primary-care physicians. From this perspective, an increase in primary-care physicians may even help to increase the supply of nurse practitioners.

The lack of correlation between the dissimilarity index and the nurse practitionerto-population ratio indicates that higher nurse practitioner-to-population ratios do not lead to an equitable nurse practitioner distribution (Table 2, fifth column). For example, Arkansas had a very high nurse practitioner-to-population ratio, but its nurse practi- 
TABLE 2 - Geographic Distribution of Nurse Practitioners by State

\begin{tabular}{|c|c|c|c|c|c|c|}
\hline State & $\begin{array}{l}\text { Number } \\
\text { of NPs }\end{array}$ & $\begin{array}{c}\text { NP-Pop. } \\
\text { Ratio }\end{array}$ & $\begin{array}{l}\text { NP-Pop. } \\
\text { Quotient }^{a}\end{array}$ & $\begin{array}{c}\text { NPs } \\
\text { per } 100 M D s^{b}\end{array}$ & $D I^{c}$ & DI Ratio ${ }^{d}$ \\
\hline AK & 218 & 39.6 & 2.979 & 50.23 & - & - \\
\hline $\mathrm{AL}$ & 339 & 8.4 & 0.630 & 11.36 & 0.2974 & 1.080 \\
\hline$A R$ & 892 & 37.9 & 2.851 & 51.71 & 0.4428 & 2.035 \\
\hline AZ & 762 & 20.8 & 1.563 & 25.66 & 0.1221 & 1.417 \\
\hline $\mathrm{CA}$ & 5757 & 19.4 & 1.456 & 20.24 & 0.1588 & 1.737 \\
\hline CO & 416 & 12.6 & 0.949 & 13.53 & 0.3233 & 1.369 \\
\hline CT & 506 & 15.4 & 1.157 & 12.99 & 0.1270 & 1.175 \\
\hline DC & 32 & 5.3 & 0.396 & 5.69 & - & - \\
\hline $\mathrm{DE}$ & 57 & 8.6 & 0.643 & 4.21 & 0.1369 & 0.917 \\
\hline $\mathrm{FL}$ & 2346 & 18.1 & 1.363 & 22.17 & 0.1841 & 1.247 \\
\hline $\mathrm{GA}$ & 632 & 9.8 & 0.733 & 12.63 & 0.2853 & 1.097 \\
\hline $\mathrm{HI}$ & 92 & 8.3 & 0.624 & 7.46 & - & - \\
\hline IA & 191 & 6.9 & 0.517 & 10.58 & 0.3077 & 0.825 \\
\hline ID & 111 & 11.0 & 0.828 & 17.51 & 0.3964 & 2.900 \\
\hline IL & 443 & 3.9 & 0.291 & 3.89 & 0.1903 & 0.952 \\
\hline IN & 364 & 6.6 & 0.493 & 9.24 & 0.3554 & 1.917 \\
\hline KS & 254 & 10.3 & 0.770 & 13.03 & 0.3335 & 0.903 \\
\hline KY & 261 & 7.1 & 0.532 & 9.41 & 0.3738 & 1.553 \\
\hline LA & 189 & 4.5 & 0.337 & 5.90 & 0.3218 & 1.433 \\
\hline MA & 1849 & 30.7 & 2.309 & 24.61 & 0.2227 & 1.170 \\
\hline MD & 675 & 14.1 & 1.061 & 10.47 & 0.2131 & 1.021 \\
\hline $\mathrm{ME}$ & 332 & 27.0 & 2.032 & 33.64 & 0.1736 & 1.110 \\
\hline $\mathrm{Ml}$ & 612 & 6.6 & 0.495 & 8.42 & 0.2970 & 1.416 \\
\hline MN & 396 & 9.1 & 0.680 & 8.84 & 0.2608 & 0.990 \\
\hline $\mathrm{MO}$ & 581 & 11.4 & 0.853 & 14.55 & 0.2555 & 1.042 \\
\hline MS & 142 & 5.5 & 0.415 & 9.11 & 0.3536 & 1.446 \\
\hline MT & 140 & 17.5 & 1.317 & 24.14 & 0.2290 & 1.873 \\
\hline NC & 680 & 10.3 & 0.771 & 12.64 & 0.3159 & 1.151 \\
\hline ND & 85 & 13.3 & 1.001 & 15.51 & 0.4129 & 1.917 \\
\hline $\mathrm{NE}$ & 67 & 4.2 & 0.319 & 5.13 & 0.3663 & 1.467 \\
\hline $\mathrm{NH}$ & 236 & 21.3 & 1.599 & 26.16 & 0.1826 & 1.165 \\
\hline NJ & 516 & 6.7 & 0.502 & 6.16 & 0.2731 & 2.081 \\
\hline NM & 260 & 17.2 & 1.292 & 20.20 & 0.2787 & 1.217 \\
\hline NV & 137 & 11.4 & 0.857 & 17.19 & 0.1491 & 1.561 \\
\hline NY & 3061 & 17.0 & 1.279 & 13.00 & 0.3065 & 1.576 \\
\hline $\mathrm{OH}$ & 443 & 4.1 & 0.307 & 4.95 & 0.3104 & 1.293 \\
\hline OK & 243 & 7.7 & 0.580 & 12.08 & 0.2619 & 1.072 \\
\hline OR & 819 & 28.8 & 2.165 & 32.58 & 0.2344 & 1.252 \\
\hline PA & 1570 & 13.2 & 0.993 & 14.03 & 0.2603 & 1.229 \\
\hline $\mathrm{RI}$ & 106 & 10.6 & 0.794 & 9.95 & 0.2280 & 1.221 \\
\hline SC & 324 & 9.3 & 0.698 & 12.27 & 0.2771 & 1.159 \\
\hline SD & 93 & 13.4 & 1.004 & 17.19 & 0.2795 & 1.199 \\
\hline TN & 568 & 11.6 & 0.875 & 13.56 & 0.3086 & 1.273 \\
\hline TX & 1350 & 7.9 & 0.597 & 10.94 & 0.2606 & 1.441 \\
\hline UT & 343 & 19.9 & 1.496 & 26.02 & 0.2431 & 1.244 \\
\hline VA & 1648 & 26.6 & 2.002 & 29.21 & 0.2147 & 0.949 \\
\hline VT & 182 & 32.3 & 2.429 & 29.26 & 0.2047 & 0.895 \\
\hline WA & 1338 & 27.5 & 2.067 & 28.57 & 0.1892 & 0.949 \\
\hline WI & 271 & 5.5 & 0.416 & 6.70 & 0.3084 & 1.610 \\
\hline WV & 96 & 5.4 & 0.402 & 6.95 & 0.4066 & 1.504 \\
\hline WY & 59 & 13.0 & 0.979 & 17.77 & 0.3677 & 2.255 \\
\hline
\end{tabular}

aNP: Population Quotient is the ratio of each state NP-population ratio divided by the national average (13.306).

${ }^{\mathrm{b}} \mathrm{MD}$ refers to primary-care physicians.

${ }^{c}$ Corrected Dissimilarity Indices (DI) are, in general, comparable between states-the higher the number, the greater the concentration. AK, DC, and $\mathrm{HI}$ were not included.

dThe Dissimilarity Index ratio, which is the ratio of Nurse Practitioner-Population Dissimilarity index divided by PhysicianPopulation index, is comparable between states. NPs are distributed as equitably as primary-care physicians according to population when the Dissimilarity Index ratio equals 1 ; when the index ratio is greater than 1 , NPs are more concentrated than physicians. 
tioner distribution was highly concentrated, with more than a third of nurse practitioners in the capital, Little Rock. As a result, the dissimilarity index for Arkansas was 0.44, the highest of all. Conversely, Illinois and Nevada had very low nurse practitioner-topopulation ratios, but their nurse practitioners were more equitably distributed than in most other states, resulting in very low dissimilarity indexes. There were also some states with a relatively high nurse practitioner-to-population ratio, such as Maine, that maintained reasonably balanced distributions.

Finally, the geographic distributions of nurse practitioners and primary-care physicians were compared within each state. The results (Table 2, seventh column) showed that nurse practitioners in 40 states were less equitably distributed than primary-care physicians. Eight states (Delaware, Idaho, Illinois, Kansas, Minnesota, Virginia, Vermont, and Washington), had a more equitable distribution of nurse practitioners than of primarycare physicians (results for Alaska, the District of Columbia, and Hawaii could not be calculated). This appears to be true for states with low nurse practitioner-to-population ratios and for states with higher nurse practitioner-to-population ratios. The most notable exceptions were Virginia, Vermont, and Washington, where nurse practitioners were more equitably distributed than the primary-care physicians and nurse practitioner-topopulation ratios were relatively high.

To summarize, nurse practitioners were more concentrated than primary-care physicians at both the national and state levels. At the national level, they were highly concentrated in the counties with large central cities. Nurse practitioner-to-population ratios varied widely between states. The ratios were positively correlated with the ratios of nurse practitioners to primary-care physicians, but were not associated with their distribution pattern within each state.

\section{MULTIVARIATE ANALYSES OF NURSE PRACTITIONER DISTRIBUTIONS}

This section examines nurse practitioner distributions at the county level. A map of the distribution of county-based nurse practitioners is shown in Figure 1. A logistic regression was used to compare counties with and without a nurse practitioner (depicted in the map as shaded vs. white). For counties with at least one nurse practitioner, an ordinary least-squares (OLS) regression analysis was used to evaluate nurse practitioner-topopulation ratios (depicted in the map as shading from light to dark).

\section{Logistic Regression Results}

Contrary to the effect anticipated by the Office of Technology Assessment (1986), the likelihood of having a nurse practitioner was not associated with the increasing number of primary-care physicians. Moreover, consistent with the state-level finding, counties with higher proportions of primary-care physicians were more likely to have a nurse practitioner. The presence of Health Maintenance Organizations and the number of hospital beds were not related to the presence of a nurse practitioner within a county (Table 3).

Interestingly, counties having nurse practitioners in 1980 were strongly identified with a greater likelihood of having nurse practitioners in 1994, and this result has an important implication. As we know, the early cohort of nurse practitioners tends to be in rural and under-served areas, and descriptive statistics support this claim, showing that most nurse practitioner graduates of 1980 were located in non-metropolitan counties. 


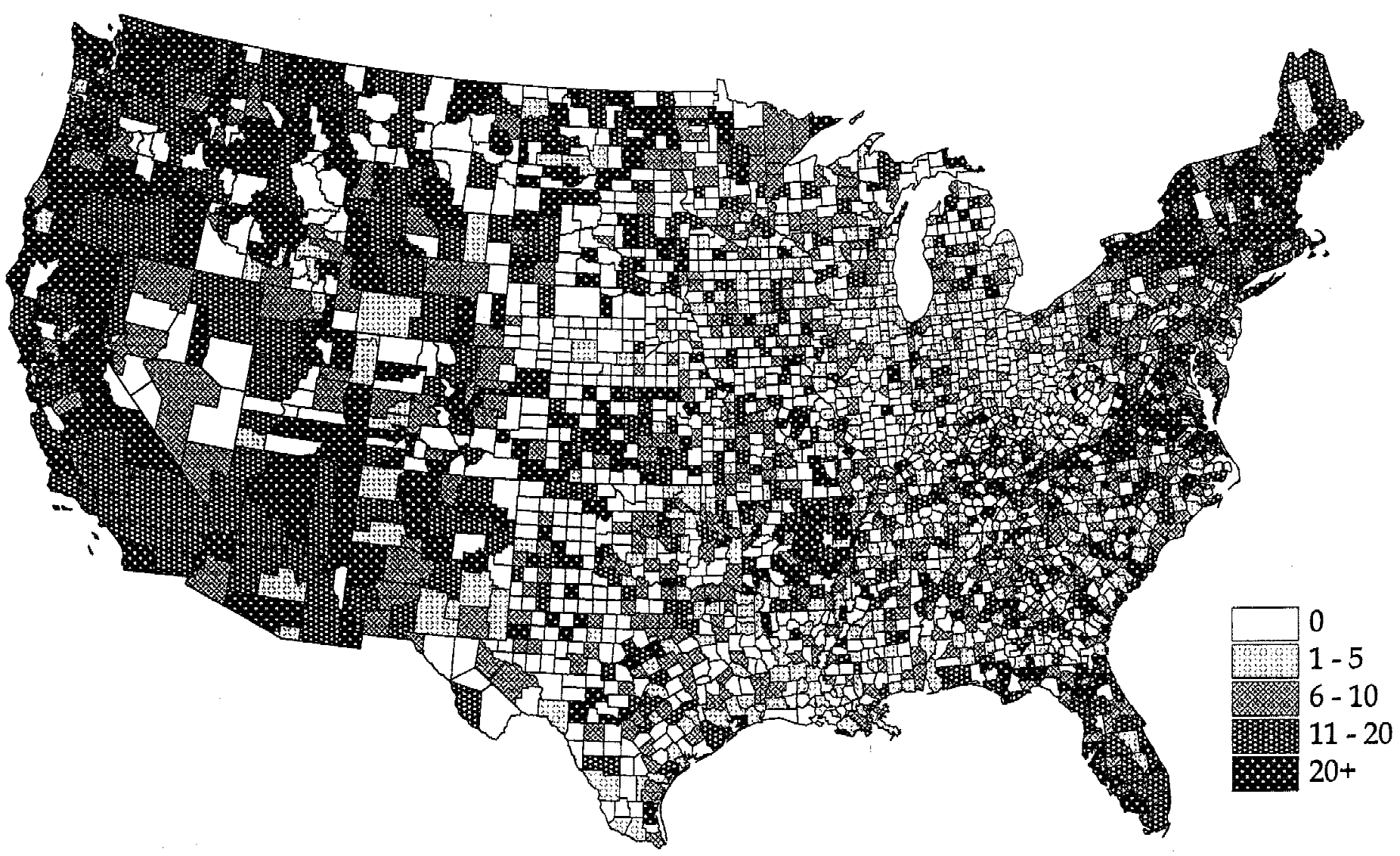

Figure 1 The number of NPs per 100,000 population in the U.S., 1994. It is difficult to display Alaska and Hawaii at the county level. At the state level, the number for Alaska is 39 and for Hawaii is 8 . 


\begin{tabular}{lrc}
\hline Variables & Coefficient & Wald Chi-Square \\
\hline Health related & & \\
Hospital beds/1000 population & -0.0044 & 0.2529 \\
Health Maintenance Organizations & 0.8489 & 2.5315 \\
Physician growth rate & -0.0006 & 0.3727 \\
Primary care MDs-to-population ratio & 0.0085 & $15.1111^{\star *}$ \\
NP population (1980) & 0.7756 & $34.5266^{* *}$ \\
County socioeconomic factors & & \\
Median home value & 1.2244 & $50.7877^{\star *}$ \\
Per capita income & -0.7797 & $5.7372^{* *}$ \\
Percent below poverty level & 0.0035 & 0.1547 \\
Practice environment & & \\
Independent practice & 0.6869 & $21.0510^{\star *}$ \\
Direct reimbursement & 0.2466 & $6.6038^{* *}$ \\
Rurality & & $14.9140^{\star *}$ \\
$\quad$ Non-metropolitan counties & -0.6369 & $31.9093^{* *}$ \\
Population density & 0.3658 & $3.0417^{*}$ \\
Constant & -6.4796 & \\
-2 log likelihood & $3,111.88$ & \\
No. of observations & 2,973 &
\end{tabular}

Counties in Alaska and Virginia were not included in these equations, because Alaska was treated as a single region in the Area Resource File, and all the independent cities in Virginia were missing from the Area Resource File. ${ }^{*} p<0.10$.

${ }^{* *} p<0.05$.

This implies that the seeds planted in 1980 took deep root; although the numbers might have been changed, once a nurse practitioner located in a county, the county was very likely to have at least one nurse practitioner 15 years later.

In terms of county socioeconomic factors, the proportion of people below the poverty level did not affect the likelihood of having a nurse practitioner, whereas greater median home values and lower per capita incomes increased the likelihood. Because higher home values are generally associated with urban centers and lower incomes are generally associated with inner cities or rural areas, the effects of these factors together implied that nurse practitioners may be more likely to locate in counties that have urban centers with low per capita income.

As we anticipated, state regulatory environments were important. A county was more likely to have a nurse practitioner when the state regulatory environment was favorable for independent practice or direct third-party reimbursement. In other words, more restrictive practice environments hindered the dispersion of nurse practitioners at the county level. It also explains why the likelihood of having a nurse practitioner was highly associated with the number of primary-care physicians at the county level. If a nurse practitioner cannot practice independently, then she must work under the supervision of a physician. Although a nurse practitioner may locate in an area undesirable to physicians, she or he needs to be in close proximity to a physician in a more restrictive regulatory environment. 
Finally, nonmetropolitan counties were less likely to have a nurse practitioner than metropolitan counties. Of the counties without a nurse practitioner, $78 \%$ were nonmetropolitan. Likewise, counties with greater population density were more likely to have a nurse practitioner.

\section{OLS Regression Results}

Table 4 displays the results of the ordinary least-squares regression analysis. Consistent with state-level findings, counties with higher physician-to-population ratios also had a higher nurse practitioner population. In addition, physician growth rates in the previous 5 years were positively associated with nurse practitioner-to-population ratios. These results suggest that nurse practitioners may not be in direct competition with primarycare physicians. Rather, their supply goes hand in hand with that of primary-care physicians. Although the presence of a Health Maintenance Organization (HMO) was not related to the presence of a nurse practitioner in a county, it was positively associated with the nurse practitioner-to-population ratio in a county that had a nurse practitioner. This result is expected, and it collaborates empirical findings that HMOs tend to utilize a greater proportion of nurse practitioners in their health-care teams.

Median home value and per capita income were positively associated with a greater supply of nurse practitioners. Because big cities, the West Coast, and New England areas TABLE 4 - OLS Regression Analysis of Location Characteristics
on Nurse Practitioner-to-Population Ratio

\begin{tabular}{lcc}
\hline Variables & Coefficient & T Value \\
\hline Health related & & \\
Hospital beds/1000 population & -0.11599 & $-1.320^{* *}$ \\
Physician growth rate & 0.028389 & $2.924^{* *}$ \\
Health maintenance organizations & 5.884419 & $3.644^{\star *}$ \\
Primary-care MDs-to-population ratio & 0.02224 & $1.655^{\star}$ \\
NP population (1980) & 2.877142 & $3.085^{\star *}$ \\
County socioeconomic factors & & $-4.434^{* *}$ \\
Median home value & -3.836753 & $5.008^{* *}$ \\
Per capita income & 15.424101 & $2.371^{* *}$ \\
Percent below poverty level & 0.20367 & 1.071 \\
Practice environment & & $-4.434^{* *}$ \\
Independent practice & 1.358349 & -0.89 \\
Direct reimbursement & -3.845465 & $-11.014^{* *}$ \\
Rurality & & $-5.262^{* *}$ \\
Non-metropolitan counties & -1.026795 & \\
Population density & -5.465373 & \\
Constant & -156.37358 & \\
Adjusted $R^{2}$ & 0.19032 & \\
No. of observations & 1952 & \\
\hline
\end{tabular}

Counties in Alaska and Virginia were not included in these equations, because Alaska was treated as a single region in the Area Resource File, and all the independent cities in Virginia were missing from the Area Resource File.

${ }^{*} p<0.10$.

${ }^{* *} p<0.05$. 
tend to be positively identified with these two factors, these areas can be inferred as having greater supply of nurse practitioners (see Figure 1).

Both third-party reimbursement and population density were inversely related to the nurse practitioner-to-population ratio. From the logistic regression, we know that allowing third-party reimbursement means greater dispersion. Greater dispersion means that (a) each county would be more likely to have a nurse practitioner, and (b) nurse practitioner-to-population ratios tend to even out. Thus, allowing reimbursement means a lower concentration of nurse practitioners, and not allowing reimbursement means a greater concentration, presumably in densely populated areas. A more practical interpretation is that a collaborating physician is more accessible in a densely populated area or an urban setting than in less populated areas, and getting third-party reimbursement through a collaborating physician is the primary payment method when direct reimbursement is not available.

\section{CONGLUSION AND DISGUSSION}

In the United States, the number of nurse practitioners has more than doubled since 1980. However, a greater supply of nurse practitioners may not necessarily mean an equitable distribution of nurse practitioners within a state. Even though the distribution of nurse practitioners does not mirror that of the population, they appear to fulfill one of the original intentions of the nurse practitioner movement, that is, to improve access to health care to the poor and under-served inner city population. Our study found that $52 \%$ of the nurse practitioners were located in large urban centers with the highest inner city populations. The current distribution of nurse practitioners is consistent with the Office of Technology Assessment's expectation (1986) and an early longitudinal study by Brooks and Johnson (1986), that is, a greater concentration of nurse practitioners in urban areas and a lower concentration in rural areas. However, this pattern cannot be associated with increased competition from primary-care physicians, as was suggested by the Office of Technology Assessment.

This study confirms Sekscenski et al.'s (1994) findings regarding state laws or regulations governing nurse practitioner practice. Allowing independent practice and direct third-party reimbursement are associated with greater supply and dispersion of nurse practitioners. Furthermore, the study shows that independent practice is inversely related to population density, and positively associated with the nurse practitioner to population ratio. If these relations hold over time, allowing independent practice and direct third party reimbursement will not only increase the likelihood of having a nurse practitioner, but it will also increase the supply of nurse practitioners to less densely populated rural counties.

Within current practice environments, a greater supply of physician correlates with a greater supply of nurse practitioners. This fact actually reflects the original intention of the GMENAC (1981), which suggested an "ideal" nurse practitioner-to-physician ratio. At this stage, the dominant pattern in geographic distribution between nurse practitioners and physicians seems to be associative and complementary (LeRoy, 1994). It is worth noting, though, that the geographic substitution hypothesis between nurse practitioners and primary-care physicians could not be tested in this article, because most state laws prohibit nurse practitioners from independent practice, requiring instead that they work under the supervision of a collaborating physician. Under this legal environment having a stable relationship with a collaborative physician becomes an important factor. Because physician populations are more stable in urban communities than in rural communities, 
an urban nurse practitioner has less difficulty than a rural nurse practitioner in finding a collaborating physician. Given the fact that under-served populations are most often seen in inner cities and rural areas, everything else being equal, nurse practitioners are more likely to be used to improve access to care for the under-served population in urban areas, especially in inner cities. This result substantiates findings from the Physicians' Payment Review Commission (1994), and calls for changes in laws or regulations to give nurse practitioners greater flexibility to practice in rural areas.

In this study, we were unable to include physician assistants in the analyses. According to Jones and Cawley (1994) there are more than 23,300 physician assistants, 10,270 of whom $(44 \%)$ are in primary-care settings. An area without a nurse practitioner may have a physician assistant as a non-physician provider (Fowkes, 1993). At the state level, it has been suggested (Sekscenski et al., 1994) that the numbers of nurse practitioners and physician assistants are positively correlated. Future studies should look at their combined distribution at the county level. Studies should also look at geographic implications of utilizing nurse practitioners in different practice settings, and promote those settings that employ more nurse practitioners in under-served areas.

\section{REFERENCES}

Aiken, H.L., and Salmon, E.M. (1994). Health Care Workforce Priorities: What Nursing Should Do Now? Inquiry 31:318-329.

Brooks, E. et al. (1981). New Health Practitioners in Rural Satellite Health Centers: The Past and Future. Journal of Community Health 6:246-256.

Brooks, E., and Johnson, S. (1986). Nurse Practitioner and Physician Assistant Rural Satellite Health Centers: The Pending Demise of an Organization Form? Medical Care 24:881-890.

Brown, D.M. (1988). Do Physicians Underutilize Aides? Journal of Human Resources 23:342-355.

Coulter, B.P. (1989). Measuring Inequality: A Methodological Handbook. Boulder, CO: Westview.

DeAngelis, C.D. (1994). Nurse Practitioner Redux. Journal of the American Medical Association 271:868871.

Division of Nursing, Bureau of Health Professions, Health Resources and Services Administration. (1994). Survey of Certified Nurse Practitioners and Clinical Nurse Specialists: December 1992. Washington, DC: Washington Consulting Group.

Ernst, R.L., and Yett, D.E. (1985). Physician Location and Specialty Choice. Ann Arbor, MI: Health Administration Press.

Fowkes, V. (1993). Meeting the Needs of the Underserved: The Roles of Physician Assistants and Nurse Practitioners. In D. Clawson and M. Osterveis (Eds.), The Role of Physician Assistants and Nurse Practitioners in Primary Care. Washington, DC: Association of Academic Health Centers.

GAO (United States General Accounting Office). (1995). Health Care Shortage Areas: Designations Not a Useful Tool for Directing Resources to the Under-Served. Report to Congressional Committees No. GAO/HEHS-95-200.

Graduate Medical Education National Advisory Committee (GMENAC). (1981). Summary report of the Graduate Medical Education National Advisory Committee to the Secretary, Department of Health and Human Services Pub. No. HRA-81-651. Washington, DC: U.S. Government Printing Office.

Hadley, J. (1994). Workforce Policies: Physicians and Nurses in Health Care Reform. Inquiry 31:342343.

Hewitt, M. (1989). Defining a Rural Area: Impact on Health Care Policy and Research. Staff Paper, Office of Technology Assessment, Congress of the United States.

Jones, E.P., and Cawley, J.F. (1994). Physician Assistants and Health System Reform. Journal of the American Medical Association 271:1266-1272.

Koch, L.W., Pazaki, S.H., and Campbell, J.D. (1992). The First 20 Years of Nurse Practitioner Literature: An Evolution of Joint Practice Issues. American Journal of Primary Health Care 17:62-71. 
Langwell, K.M., Drabek, J., Nelson, S.L., and Lenk, E. (1987). Effects of Community Characteristics on Young Physicians' Decisions Regarding Rural Practice. Public Health Reports 102:317-328.

LeRoy, L.B. (1994). Meeting the Challenge: A Health Workforce Prepared for the Future. Inquiry 31:334-337.

Martin, S., and Martin, D. (1991). Nurses as Primary Care Providers in Rural America. In A. Bushy (Ed.). Rural Nursing (Vol. 2, pp. 198-208).

Newhouse, J.P., Williams, A.P., Bennett, B.W., and Schwartz, W.B. (1982). Where Have All the Doctors Gone? Journal of the American Medical Association 247:2392-2396.

Office of Management and Budget. (1990). Revised Standards for Defining Metropolitan Areas in the 1990's. Federal Register 55:12156.

Office of Technology Assessment. (1986). Nurse Practitioner, Physician Assistants, and Certified Nurse Midwives: A Policy Analysis. Washington, DC: U.S. Government Printing Office.

Pew Health Professions Commission. (1995). Critical Challenges: Revitalizing the Health Professions for the Twenty-First Century, Pew Health Professions Commission, San Francisco, CA.

Physicians' Payment Review Commission. (1994). Annual Report to Congress, Nonphysician Practitioners. Washington, DC: PPRC.

Rivo, M.L., and Satcher, D. (1993). Improving Access to Health Care through Physician Workforce Reform: Directions for the 21st Century. Journal of the American Medical Association 270:10741078.

Safriet, J.B. (1992). Health Care Dollars and Regulatory Sense: The Role of Advanced Practice Nursing. Yale Journal on Regulation 9:419-488.

Safriet, J.B. (1994). Impediments to Progress in Health Care Workforce Policy: License and Practice Laws. Inquiry 31:310-319.

Schwartz, W.B., Newhouse, J.P., Bennett, B.W., and Williams, A.P. (1980). The Changing Geographic Distribution of Board-Certified Physicians. New England Journal of Medicine 303:1032-1038.

Sekscenski, E., Sansom, S., Bazell, C., Salmon, M.E., and Mullan, F. (1994). State Practice Environments and the Supply of Physician Assistants, Nurse Practitioners, and Certified NurseMidwives. New England Journal of Medicine 331:1266-1271.

Spitzer, W.O., Sackett, D.L., and Sibley, J.C. (1974). The Burlington Randomized Trial of Nurse Practitioners. New England Journal of Medicine 290:251-256.

Sullivan, J., Dachelet, C., Sultz, H., and Henry, M. (1978). The Rural Nurse Practitioner: A Challenge and a Response. American Journal of Public Health 68:972-976.

Sultz, H. et al. (1980). Longitudinal Study of Nurse Practitioners, Phase II, Pub. No. HRA-80-2. Washington, DC: U.S. Government Printing Office.

Sultz, H., Henry, O.M., Kinyon, J.L., Buck, G.M., and Bullough, B. (1983a). A Decade of Change for Nurse Practitioners. Nursing Outlook 3:138-141.

Sultz, H., Henry, O.M., and Sullivan, A.J. (1983b). Nurse Practitioners: USA. Lexington, MA: Lexington Books.

Sultz, H., and Zielezny, M. (1976). Longitudinal Study of Nurse Practitioners, Phase I, Pub. No. HRA-76-43. Washington, DC: U.S. Government Printing Office.

U.S. Department of Health and Human Services, Bureau of Health Professions. (1988). The Registered Nurse Population: Findings from the National Sample Survey of Registered Nurses, March 1988. Washington, DC: National Technical Information Service.

U.S. Department of Health and Human Services, Bureau of Health Professions. (1994). Office of Data Analysis and Management. Rockville, MD.

U.S. Department of Health and Human Services, Bureau of Health Professions. (1995). Report on Primary Care Workforce Projections. Rockville, MD: Council on Graduate Medical Education National Advisory Council on Nurse Education \& Practice.

Weiner, J.P., Steinvachs, D.M., and Williamson, J.W. (1986). Nurse Practitioner and Physician Assistant Practices in Three Health Maintenance Organizations: Implications for Future US Health Manpower Needs. American Journal of Public Health 76:507-511.

Weiner, J.P. (1993). The Demand for Physician Services in a Changing Health Care System: A Synthesis. Medical Care Review 50:411-449. 